\section{Det Kongelige Kapels ældste kapelmester identificeret}

\author{
Af seniorforsker Ole Kongsted
}

$\sqrt{1}$ t betydningsfuldt fund i stadsarkivet i Nürnberg har kastet nyt lys over Det Kongelige Kapels ældste historie, idet Kapellets hidtil ældste kendte kapelmester nu er identificeret: Den fra det bemærkelsesværdige regnskab 1519 kendte „Hern Conradt" (se ill. 1 ) har vist sig at være identisk med Conrad Rein (ca.14751522). " Identifikationen er selvsagt ikke blot betydningsfuld i forbindelse med et nyt og nu mere detailleret syn på denne komponist; vigtigere er naturligvis, at den har interessante konsekvenser for studiet af den ældre danske musikhistorie. Jeg skal i anden sammenhæng i detailler vende tilbage til denne vigtige nyopdagelse, som kort skal refereres her.

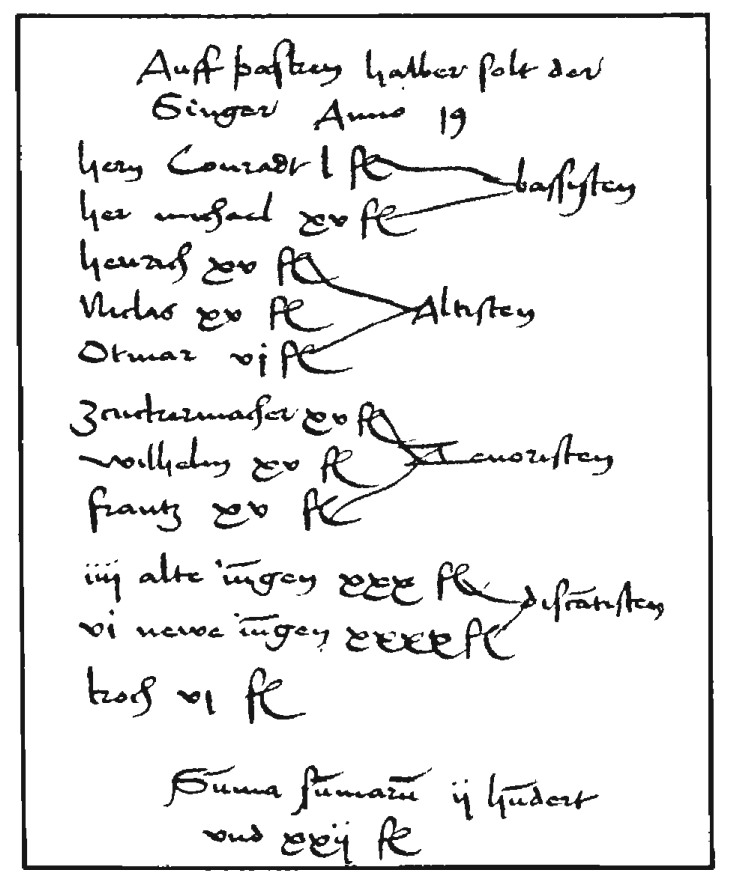

- Ill.1: Regnskab fra 1519. Se note 1.
$\mathrm{D}$ er har været flere bud på, hvem den mystiske anonyme ,herr Conradt"kunne være; flere

„Conrad'er" har været bragt i forslag: den nu identificerede Conrad Rein, hof-

kapelmesteren Conrad Rupsch i Torgau, ${ }^{2)}$ og der kunne for så vidt også have været tale om den „Märker" [= fra Brandenburg] herr Conrad, som Christian II havde hos sig. ${ }^{3 \prime}$ Af et dokument i stadsarkivet i Nürnberg fra 1522 - fremdraget af to tyske forskere, Karl Kohn og Friedhelm Brusniak - fremgår imidlertid nu, at „Cunraden Rain zu Koppenhagen inn Dennmarckt" (se ill. 2) har været en slags executor testamenti - og også kreditor i boet - efter den i Stockholm under 12. maj eodem anno afdøde tyske præst, herr Michael Schelkopff. ${ }^{+1}$

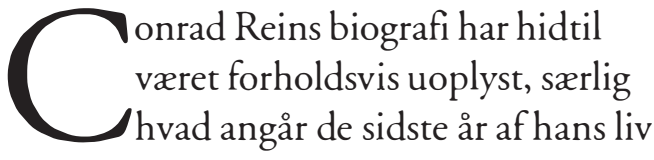

1515-1522. Han var født i Arnstadt i

Thüringen. Ikke længe efter 1500 blev han ansat som skolemester ved Heilig-GeistSpital i Nürnberg, hvor han i 1507 blev præsteviet. I stillingen som rektor blev han indtil først pååret 1515. Hvad der skete i de sidste $71 \frac{1}{2}$ ar af hans liv, har hidtil henligget $\mathrm{i}$ det dunkle. ${ }^{5}$ Disse år er der nu kastet nyt lys over ved fundet af ovennævnte dokument.

S amtidig er dukket oplysninger op, der afslører, hvorledes kontakten imellem den danske kong Christian II og Rein er kommet i stand." Som en af tre gesandter, der skulle føre forhandlinger med kejser Maximilian i forbindelse med det kommende ægteskab imellem den danske konge og kejserens barnebarn, Isabella (15011526), rejste biskop Godske Ahlefeldt af Slesvig (se ill. 3 ) i 1514 til kejseren i Linz, hvor ægteskabskontrakten skulle indgås." 
$\sqrt{1}$

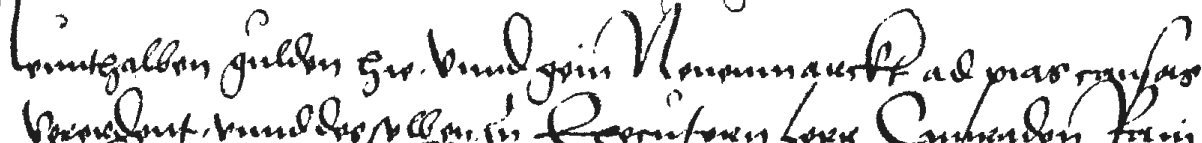

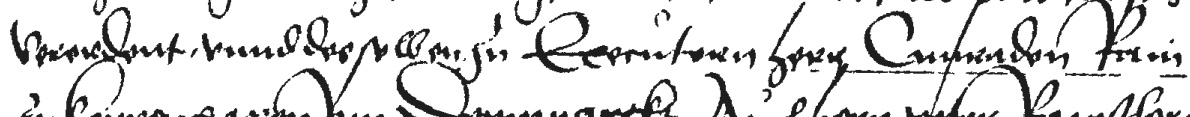

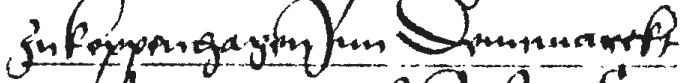

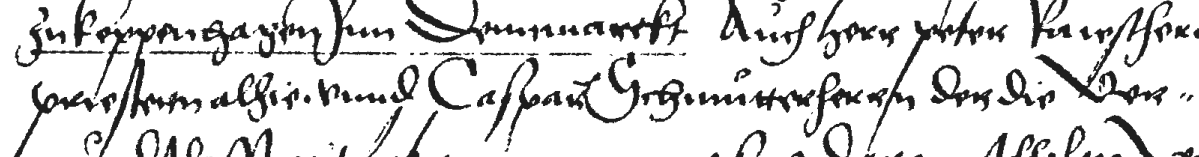

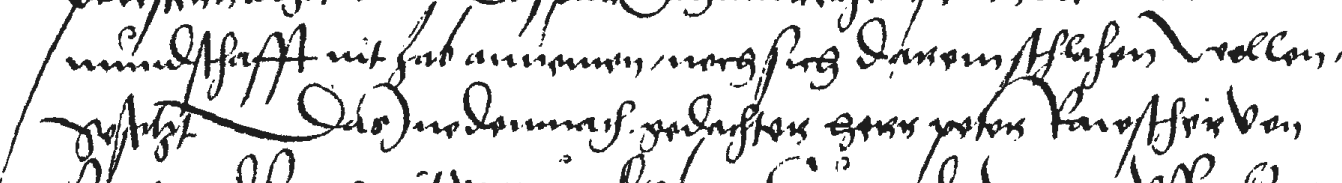

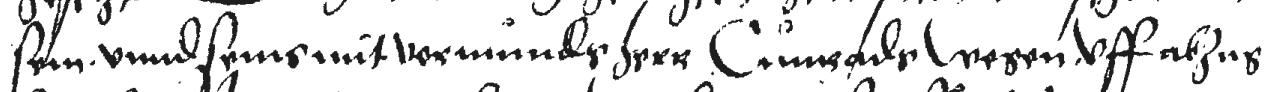

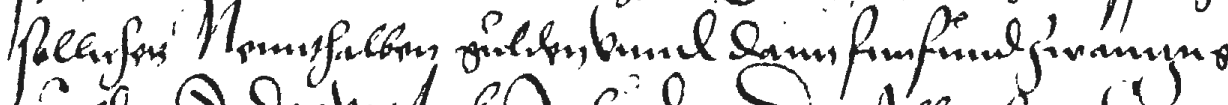

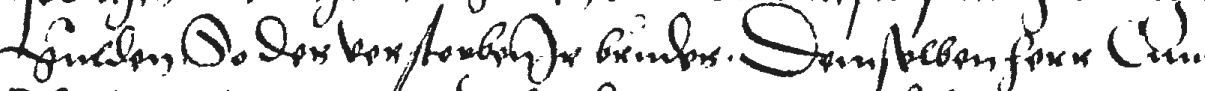

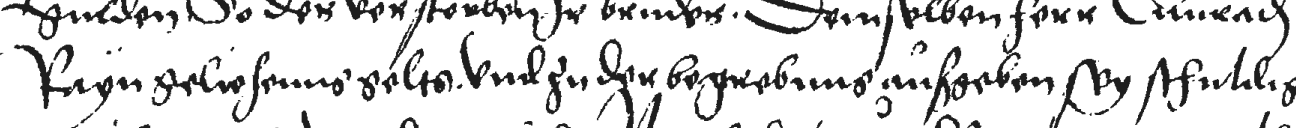

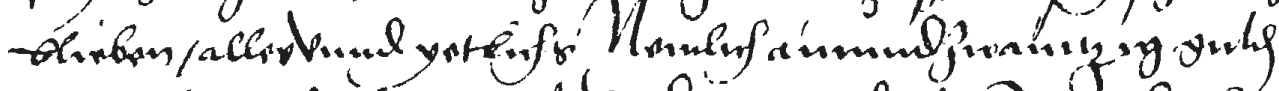

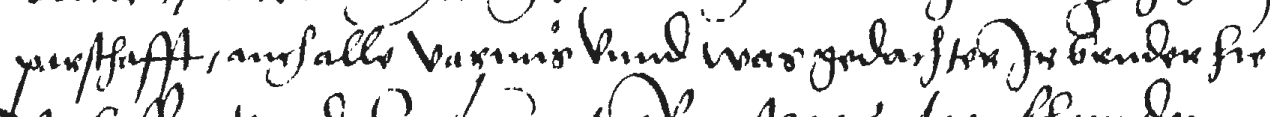

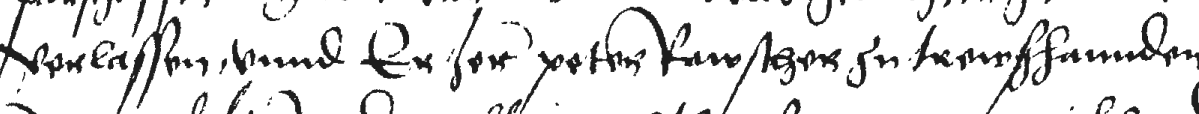

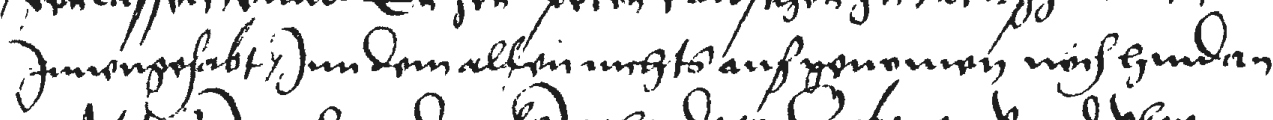

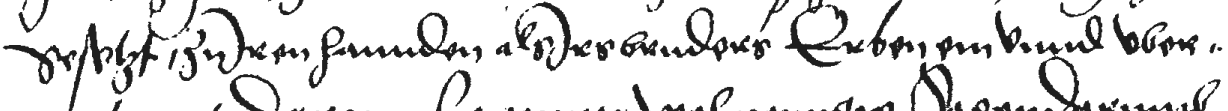

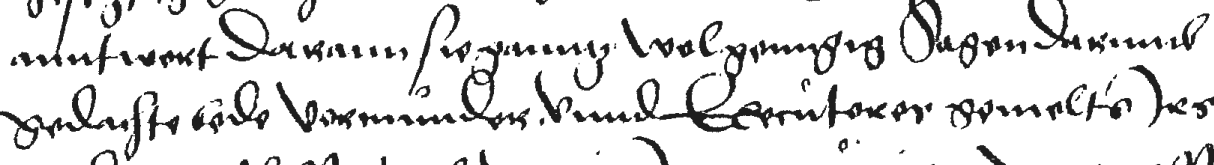

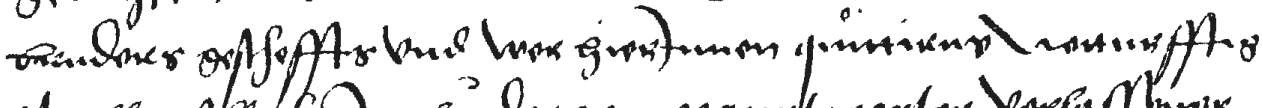

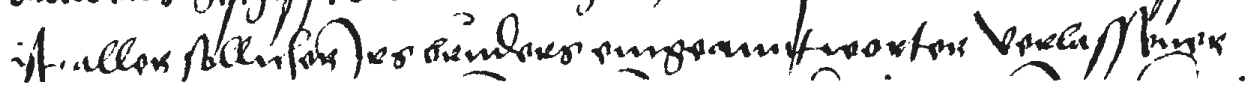

Ill. 2: Dokumentet fra stadsarkivet i Nürnberg der afslorer; at regnskabets herr Conrad er identisk med Conrad Rein. Se note 4.

Biskoppen - en betydelig personlighed, som ifølge samtidige beretninger skal have været en både begavet og statelig herre - skrev en rejsedagbog, som er opbevaret i Rigsarkivet. ${ }^{81}$ Her er rejseruten afsløret; rejsen gik bl.a. over Torgau, hvor kurfyrstens smukke hofmusik fremhæves og senere over Nürnberg, hvortil selskabet ankom i marts 1514. Bispen og hans følge blev behandlet med den respekt og imødekommenhed, som tilkom et kongeligt gesandtskab; byrådet trakterede „des Königs von Tennemarcktz potschaft" med 32 „Kandel Wein“, informerede om byens politiske, militære og økonomiske forhold, ligesom der blev givet en lejlighed til at se "das Heiltum“: Heilig-Geist-Spital, hvor rigsklenodier og relikvier blev opbevaret. Det er rimeligt at antage, at biskop Godske og herr Conrad har truffet hinanden ved denne lejlighed. Conrad Rein var som „Schulmeister" leder af skolens vokalmusik - et kantori, der blev meget rost $\mathrm{i}$ samtiden; det forekommer plausibelt, at bispen - som kan have fået en prøve på Reins' kunnen ved denne lejlighed - har ladet en bemærkning falde i København, 
hvor det stod klart, at en organisering/ reorganisering af majestætens kapel var nødvendig - ikke mindst med anledning i det forestående bryllup og dronningens kroning.

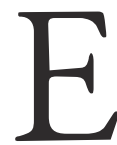
n samtidig beretning afslører nemlig, at det stod slemt til med sangen i kongens København. Skt. Georgs dag 1515 skrev Hans Valkendorf, som studerede ved universitetet i Louvain, til sin broder, ærkebiskop Erik af Trondhjem, at om det var således, at Hans Nåde [= kongen] ingen sangere havde, "... tha wore thet meget got ath Hans Nadx lod hente the aff Lybke [= Lübeck] eller nogen aff Danskenn [= Danzig] ... thii thee songe ther meget ildæ wti Køpnehaffn "." Da Hans Valkendorf skrev sit brev [23. april 1515], var aftalen med Conrad Rein sandsynligvis allerede indgået og sidstnævnte muligvis allerede til stede i eller på vej til København. I hvert fald fik Rein sin sidste løn i Nürnberg udbetalt d. 17. februar 1515. ${ }^{1(1)}$ Det er rimeligt at antage, at han var til stede i Kobenhavn i god tid før brylluppet, som fandt sted d. 12. august samme år. Imidlertid dukker herr Conrad først op i danske kilder i det ovenfor nævnte regnskab fra 1519, hvor han som sangmester modtog den formidable gage af 50 floriner. Da der er tale om en halvårsudbetaling, har Conrad Rein altsă făet 100 floriner årligt. Dette faktum har fåt nogle historikere til at antage, at regnskabet 1519 ikke kunne være dansk, idet man har haft svært ved at forestille sig, at Christian II havde så mange penge at anvende på sin hofmusik. "' Denne smukke sum var da også meget større end den løn, Rein blev betalt i Nürnberg, og som det ses - også væsentlig større end de bedst gagerede af de øvrige sangere, som fik . 30) floriner årligt.

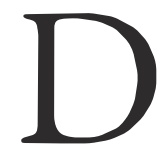
et kongelige kantori bestod i 1519 jævnfør dette regnskab af ti drenge, tre mandlige altister

(kontratenorer), tre tenorer og to bassangere. Der er på listen kun anført en person med et (tysk) slægtsnavn; alle andre personer har tyske fornavne, og det må formodes, at der for alles/de flestes vedkommende er tale om sangere, der blev engageret samtidig med Rein - måske endda folk, som han havde med fra Nürnberg. De øvrige sangere er endnu i skrivende stund anonyme bortset fra - som jeg formoder - to personer. Den anden af bassangerne er en herr Michael altså en præst - muligvis netop den Michael Schelkopff, der senere døde i Stockholm. En af altisterne - Henrich - er efter alt at dømme identisk med musikteoretikeren Heinrich Faber. ${ }^{12)}$ Efter otte års tro tjeneste hos Christian II, forsøgte denne i forbindelse med rejsen fra Danmark at hjælpe sin musiker til en ny stilling. Den 8. juni 1523 skrev Christian II fra Wittenberg til den sachsiske kurfyrste, Friedrich der Weise, at " ... Hainrich Lichtenfels, zayger dytz brieffs, vnns in Solcher vnserer Canterey eine Zeitlang vnnd byss in das Neundte Jar fur einen altysten gedint", at han havde været tjenstvillig og tro, og at Christian II anbefalede ham til kurfyrstens velvilje, da det jo var bekendt, at denne havde ,... ein Canterey, die nit wenig Rumbs oder Lobs haben". Brevet - som er et smukt vidnesbyrd om kong Christians omsorg for sine musikere fik, såvidt det kan oplyses, ikke den ønskede effekt. ${ }^{131}$

$\mathrm{I}$ dentifikationen af Conrad Rein er af flere grunde særdeles betydningsfuld, naturligvis ikke mindst for dansk musikhistorisk forskning: pro primo for en sikker viden om Det Kongelige Kapels fortid rykkes næsten en generation tilbage i tid, pro 


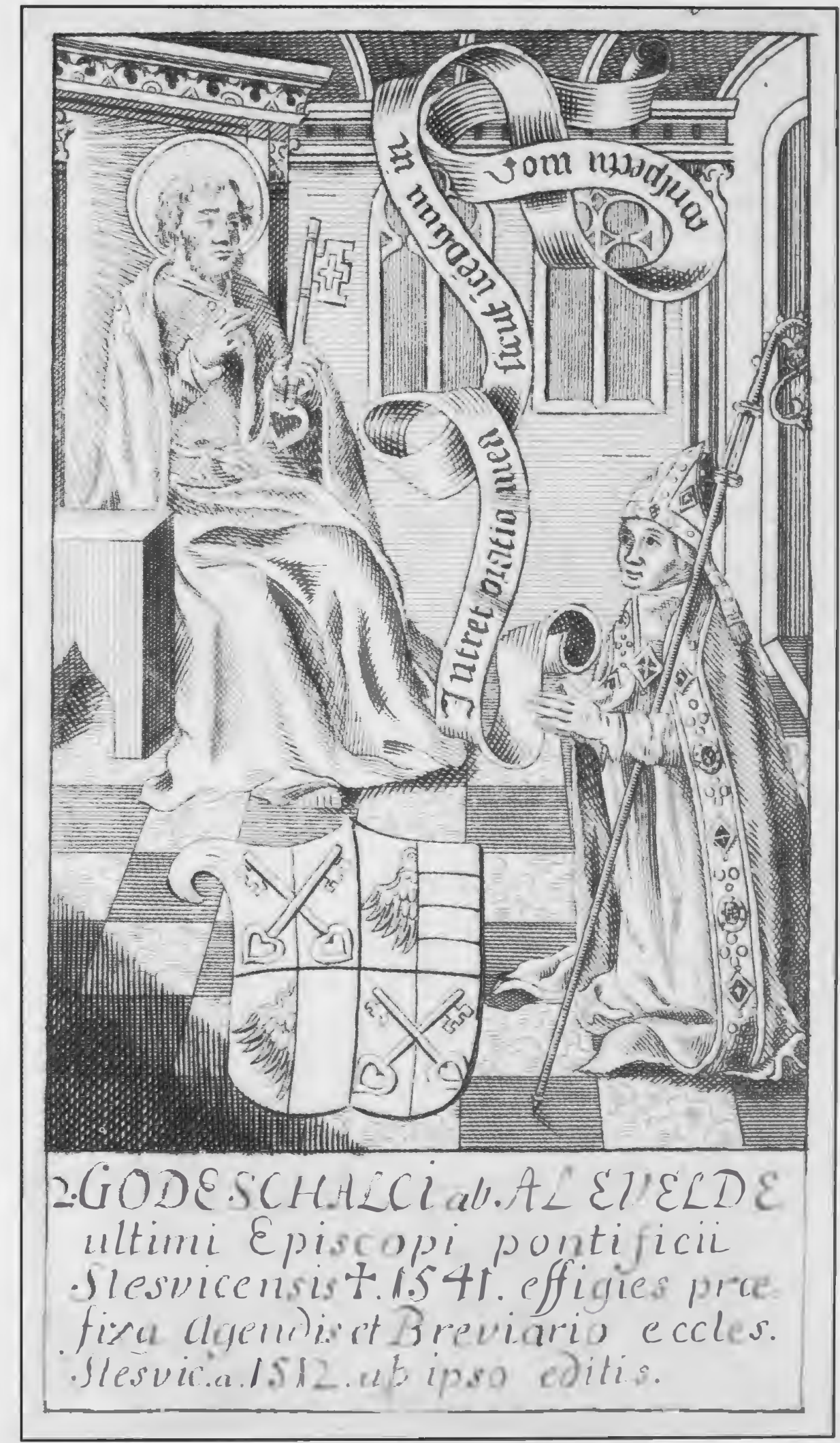

Ill. 3: Biskop Godske Ahlefeldt. (Fra Breviarium Slesvicense, 1512). 
secundo fordi Rein af den samtidige teoretiker Ornitoparchus nævnes på linie med nogle af samtidens fineste musikere, ${ }^{14)}$ pro tertio fordi Det Kongelige Kapel hermed placeres i „europæisk klasse“ allerede før Reformationen - og sidst men ikke mindst, fordi der i et halvt dusin tyske forskningsbiblioteker er overleveret en snes værker af Reins tilvirkning, hvorfor det vil være muligt at studere denne den første danske hofkapelmesters musik i detailler (se ill. 4). Det drejer sig udelukkende om liturgisk musik på latin $\mathrm{i}$ genrerne: messe, magnificat og motet. Hvad der nu står for, er selvsagt en nøjere undersøgelse af Reins samlede opus, som har et vægtigt forlæg i Friedhelm Brusniaks monografi (1980), en cd-indspilning af et udvalg af værkerne samt en udgivelse af samtlige værker. En sådan er planlagt og vil finde sted, så snart det praktisk kan lade sig gøre i et samarbejde imellem undertegnede og Professor, Dr. Friedhelm Brusniak, Würzburg. Udgivelsen er finansieret af Dagny og Knud Gad Andresens Fond.

Identifikationen af Conrad Rein er endnu et vidnesbyrd om hidtil ukendte kulturelle forbindelser imellem Nürnberg og København. Tidligere forbindelser er påvist bl.a. i sammenhæng med det danske hofs indkøb af nürnbergske musikinstrumenter. Forbindelsen Nürnberg-København har som bekendt først og fremmest været dokumenteret ved Frederik IIs bestilling af Labenwolffontænen i 1570'erne og senest ved fundet af "Kronborg-motetterne" af Leonhard Lechner. ${ }^{151}$

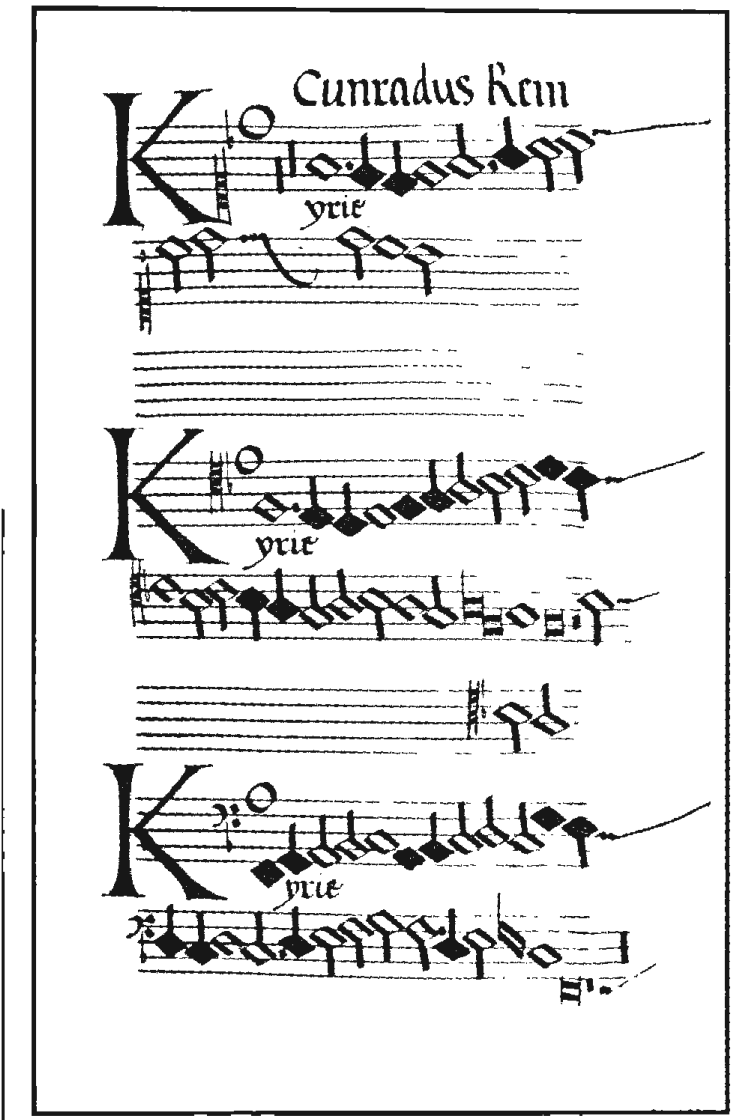

Ill. 4: Forste side afkorbogen, UB Erlangen Ms. 473, 1, fol.175uff, med Discantus, Tenor og Bassus til Conrad Reins „Missa Super Accessit ad pedes Jesu" 5 vocum.

Noter

1) Regnskabet - som ligger i Rigsarkivet, Reg.108A, S 12 i Pk. „Adsk. Stk. kgl. Indtægtsregnskaber 1513-1533", læg 10 har været kendt og er nævnt af flere historikere: Det er første gang publiceret i tilknytning til artiklen „Laurentii

Wermanni de obsidione Holmiensi epistola" i: Handlingar rörande Skandinaviens Historia, XXXII, Stockholm 1851, s. 57-64.

Senere er det omtalt af C.F. Allen: De tre nordiske Rigers Historie under Hans, Christiern den Anden, Frederik den Forste, Gustav Vasa, Grevefeiden 1497-1536, Andet 
binds første bog, Kbh. 1865, s. 227, af Angul Hammerich: Dansk Musikhistorie indtil ca. 1700, Kbh. 1921, s. 125 samt af Georg Galster: Danske Middelalderlige Regnskaber, 1. Rk. 1. Bd.: Hof og Centralstyre, Kbh. 1953, s. 156f. Senere under rettelser s. 835 anfører Galster - uforståeligt hvorfor -: „Sangeres Sold 1519 burde udgaa med Henvisning til Handl. rör. Skandinaviens Hist. XXXII, 1851, s. 64." - Opdagelsen af dokumentet i Nürnberg er gjort af Karl Kohn, Nürnberg, der har meddelt fundet til Friedhelm Brusniak, Würzburg, forfatter til hovedværket om Rein: Conrad Rein (ca. 1475-1522) Schulmeister und Komponist $(=$ Neue Musikgeschichtliche Forschungen, 10, Wiesbaden 1980. Jeg takker Professor, Dr. Friedhelm Brusniak for at have delt sin viden med mig samt for at have ladet mig læse sit manuskript „Zur Identifikation Conrad Reins als Leiter der Hofkantorei König Christians II. von Dänemark“, som senere udkom i: Neues Musikwissenschafiliches Jahrbuch, Jg. 8, 1999, s. 107113. Se endvidere artiklerne om Conrad Rein i: Die Musik in Geschichte und Gegenwart (MGG), bd. 11, Kassel 1963, sp. 178 samt The New Grove Dictionary of Music and Musicians (NGD), vol. 15, London 1980, s. 713.

2) Se Peters-Marquardt, Frantz: „War Hainrich Lychtenfels der spätere Musiktheoretiker Heinrich Faber?, i: Hans Albrecht in Memoriam, Kassel 1962, s. 7580; endvidere MGG, bd. 11, Kassel 1963. s. 124 samt Martin Ruhnke: Beiträge zu einer Geschichte der deutschen Hofmusikkollegien im 16. Jahrhundert, Berlin 1963, s. 221f

3) Se Behrmann, Heinrich: Geschichte Christian II, Königs von Dännemark, Norwegen und Schweden, Kopenhagen/Leipzig 1805, s. 107.

4) Stadtarchiv Nürnberg, Rep. B 14/II (Libri conservatorii), Bd. 15, fol. 187v-188v.
5) Brusniak: op.cit. (1980), s. 34-36.

6) Staatsarchiv Nürnberg, Bestände Briefbücher 72, fol. 51 (12.3.1514), Ratsverlässe 568, fol. 14 og 16v (14.3. og 15.3. 1514).

7) Se artiklen af Bjørn Kornerup i: Dansk Biografisk Leksikon, bd. 1, Kbh. 1979, s. $89 f$.

8) Dagbogen er trykt hos J.H. Schlegel: Sammlungen zur dänischen Geschichte, II/4, Kopenhagen 1776, s. 110.

9) Her citeret efter Angul Hammerich: op.cit. s. 54.

10) Se Friedhelm Brusniak: op.cit. (1980), s. 75.

11) Se Georg Galster: op.cit s. 835

12) Christoph Stroux: Die Musica Poetica des Magisters Heinrich Faber, Port Elizabeth 1976, s. 3-8. Stroux anfører som mulighed, at Faber kunne have været Reins elev i Nürnberg, hvilket dog ikke kan verificeres i den navnefortegnelse over 'chorales' i Nürnberg, som Brusniak (1980) gengiver s. $298 f f$.

13) Heinrich Faber nævnes således ikke i listen over kurfyrst Johannes („der Beständige“) musikere i Torgau/Weimar 1525; han kan dog eventuelt have været medlem af det hofkapel, der i dette år blev opløst som følge af kurfyrst Friedrichs (,der Weise") død.

14) Rein nævnes i Ornitoparchus: Musicae activae micrologus, Leipzig 1517, med Josquin, Isaac, Finck og andre blandt de musikere, i hvis værker, der er balance imellem "sensus“ og "ratio“.

15) Se Ole Kongsted: Kronborg-Brunnen und Kronborg-Motetten. Ein Notenfund des spaten 16. Jahrhunderts und seine Vorgeschichte, Kopenhagen/Flensburg/Kiel 1991 [= Schriften der Gesellschaft für Flensburger Stadtgeschichte, Bd. 43]; se endvidere Ole Kongsted: „Kronborg-motetternes komponist", i: Dansk Arbog for Musikforskning, XX, 1992, København 1993, s. 7-18. 